Article

\title{
Research Trend on the Use of IT in Digital Addiction: An Investigation Using a Systematic Literature Review
}

\author{
Flourensia Sapty Rahayu ${ }^{1, *}$, Lukito Edi Nugroho ${ }^{2}$, Ridi Ferdiana ${ }^{2}$ and \\ Djoko Budiyanto Setyohadi ${ }^{3}$ (D) \\ 1 Program Studi Sistem Informasi, Universitas Atma Jaya Yogyakarta, \\ Daerah Istimewa Yogyakarta 55281, Indonesia \\ 2 Departemen Teknik Elektro dan Teknologi Informasi, Universitas Gadjah Mada, \\ Daerah Istimewa Yogyakarta 55281, Indonesia; lukito@ugm.ac.id (L.E.N.); ridi@ugm.ac.id (R.F.) \\ 3 Magister Informatika, Universitas Atma Jaya Yogyakarta, Daerah Istimewa Yogyakarta 55281, Indonesia; \\ djoko.budiyanto@uajy.ac.id \\ * Correspondence: sapty.rahayu@uajy.ac.id; Tel.: +62-8112808638
}

Received: 8 September 2020; Accepted: 15 October 2020; Published: 18 October 2020

check for updates

\begin{abstract}
Despite the negative role of IT in digital addiction development, IT may have a positive role in dealing with digital addiction. The present study undertakes a systematic literature review to explore the state of play and the trend regarding the use of IT in digital addiction research. Using predefined keywords, the Scopus database was searched for relevant literature published from 2017 to 2020. The initial search found 1655 papers. Six stages of study selection were completed using a set of inclusion and exclusion criteria. The study selection and quality assessment process were applied, then 15 papers were selected for further review. The results show that addiction detection using IT is the most researched topic in digital addiction research. The most commonly used IT in the selected studies are AI methods and biosignal recording systems. Various approaches in detection, prevention, and intervention are suggested in the selected studies. The advantages and limitations of each approach are discussed. Based on these results, some future research directions are suggested.
\end{abstract}

Keywords: information technology; digital addiction; internet addiction; detection; prevention; intervention

\section{Introduction}

Digital addiction is a new phenomenon that has arisen as a consequence of digital technology advancement. Digital addiction is considered to be a type of technological addiction. Technological addiction is a nonchemical (behavioral) addiction involving human-machine interaction [1]. Digital addiction shares some features with other behavioral addictions, namely, (1) salience (the use of digital technology becomes the most crucial activity in a person's life and dominates their thinking, feelings, and behavior), (2) mood modification (the affected person has subjective experiences as a result of digital technology use), (3) tolerance (an increasing amount of digital technology is used to achieve the effect of mood modification), (4) withdrawal symptoms (physical effects and/or unpleasant feelings that a person experiences when internet use is suddenly stopped or decreased), (5) conflict (various types of conflict arise because of the large amount of time the user is engaged with the internet), and (6) relapse (a repeating pattern of excessive internet use after having some period of abstinence or control) [2]. Digital addiction is also defined as the problematic use of digital devices where a person develops characteristics such as being impulsive, compulsive, excessive, and hasty [3]. The term "internet addiction" is more popular than the term "digital addiction", although frequently 
both terms are used interchangeably to describe the same phenomenon. The definition of internet addiction is still being debated by many researchers [4]. Therefore, various other terms have been proposed by different researchers to replace "internet addiction", including "problematic internet use", "pathological internet use", and "compulsive internet use". For consistency, in this paper, we use the term "digital addiction" to represent the same phenomenon.

Digital addiction has several forms, including (1) cyber sexual addiction (compulsive access to sex and porn websites), (2) cyber-relationship addiction (overinvolvement in online relationships), (3) net-compulsions (online gambling, online gaming, obsessive shopping, or day trading), (4) information overload (excessive web surfing or database searching), and (5) computer addiction (obsessive non-online computer gaming) [5]. With the increase in the use of new digital technologies, such as smartphones and social media, new types of addiction have emerged [6,7].

One form of digital addiction that has been mentioned formally in section III of the fifth edition of the Diagnostic and Statistical Manual of Mental Disorders (DSM-5) as a condition that must be studied further is "internet gaming disorder". Meanwhile, the other forms of digital addiction are not yet considered as formal mental disorders. Although digital addiction has not been recognized as a formal mental disorder as yet, previous research shows that digital addiction shares similar symptoms to those seen in substance addiction $[8,9]$.

Like any other substance addiction, digital addiction can have negative impacts on a person's life. Some negative life experiences linked with digital addiction include familial disruption, work performance problems, invasion of the privacy of others, dietary-related problems, harm (self-harm, harm to others, and harm from others), emotional problems, personal problems, and social problems [10]. Infidelity in a relationship, which sometimes ends in divorce, has been identified as One of the negative impacts that digital addiction has on family relationships [11,12]. Digital addiction has also been proven to decrease a person's performance at work [13]. Previous studies show that students with digital addiction have lower levels of academic performance [14,15]. The excessive use of digital technology such as the internet can also have a variety of impacts on a person's physical health. These impacts include fatigue and lack of sleep [16]. This physical condition could lead to more serious physical health problems such as back pain, eye strain, and carpal tunnel syndrome [17]. Digital addiction could also trigger negative emotions such as anger, sadness, and fear [18]. Moreover, digital addiction can also significantly affect social connectedness [19]. Considering the above impacts on wellbeing, considerable efforts are needed to combat digital addiction.

It is significant to have a comprehensive understanding of contributing factors to digital addiction to determine the appropriate intervention strategy. Factors that contribute to the development of internet addiction include personal factors, family/school factors, perceived Internet characteristics, and environmental variables [20]. Another study mentions socio-cultural, psychological predispositions, and specific attributes of the Internet as contributing factors to excessive engagement in Internet activities [21]. Some researchers argue that the design of an internet-based technology or application plays a significant role in creating addiction in the digital experience [22-25]. Such technologies are considered to be purposively designed to make users feel compelled to use them. Several design principles that are employed to induce a compulsive effect include the encouragement of a repetitive behavior through the use of a reward system to maximize the time the user spends with the product or service [22-24]. Those previous studies show that IT has a negative role in digital addiction development.

However, despite its negative role, IT has a potential role to overcome addiction problems. Because all types of addiction share specific characteristics, the common intervention strategies for digital addiction intervention are based on therapeutic and pharmacological strategies that are commonly used to treat other types of addiction, i.e., substance use disorders, obsessive-compulsive disorder, and impulse control disorders [26]. On the other hand, significant technological advancement, including the advancement of smart technologies, has been used to give a solution to digital addiction problems. For instance, a recent review study suggests that virtual reality provides benefits for 
assessing and treating substance use disorders and behavioral addictions [27]. Virtual reality therapy has proved to be effective in reducing the severity of gaming disorder, showing effects similar to cognitive behavioral therapy [28]. Moreover, a recent study suggests that the integration between the virtual reality that capable to obtain "digital biomarkers" data and artificial intelligence (AI) using machine learning techniques allows the optimization of individual psychological treatment strategy [29]. However, little is known about the extent of IT use in the field of digital addiction up to this date. A previous review study on e-health intervention for problematic internet use conducted in 2016 only found a small number of studies (three studies) that satisfied the selection criteria [30]. That result reflects the relative youth of the research on IT utilization in digital addiction up to 2016. We found another review study conducted in 2018 that overviews the use of technologies in the field of substance use disorders [31]. However, to the best of the authors' knowledge, no review research work has investigated the extent of IT use in the digital addiction field from 2016 until this day. Therefore, the present study aims to determine the state of play and the trend of IT utilization in digital addiction research. The state of play of IT utilization describes the extent of IT use in giving solutions to digital addiction problems up to this date. The trend of IT utilization will be observed by examining the changes in what and how IT is used for addressing digital addiction. This paper also explores possible future research directions regarding the use of IT in addressing the problems associated with digital addiction. The results of this study are expected to provide new insight into the optimal use of IT for giving solutions to digital addiction problems. This study provides two contributions. The first contribution is to present the recent state of play on the use of IT in digital addiction research. The second contribution is to suggest some research directions for developing the optimal solution using IT in combating digital addiction.

The organization of this paper is as follows: Section 2 describes the methodology used in this research. Section 3 presents the results. Section 4 discusses the results and future research directions in the use of IT in digital addiction research. Finally, Section 6 presents the conclusions and limitations of this research.

\section{Methodology}

We used a systematic review approach to find the existing groundwork on the use of IT in digital addiction research. A systematic review identifies, appraises, and synthesizes all the empirical evidence that meets pre-specified eligibility criteria to answer a given research question [32]. Systematic reviews employ a systematic and transparent process to define a research question, search for literature, assess literature quality, and synthesize findings qualitatively or quantitatively [33]. However, a systematic review never provides "answers". Systematic reviews only report as accurately as possible what is known and not known about the questions addressed in the review [34]. A systematic review has a set of core principles: (1) systematic/organized: a system or method that is designed to address the specific question is followed, (2) transparent/explicit: the method used in the review is explicitly stated, (3) replicable/updatable: the method used and the way it is reported can be repeated, repeated with modification, or updated by other researchers, and (4) synthesize/summarize: systematic reviews pull together the results in a structured and organized way [34].

The review protocol used in this study follows the guidelines proposed by Kitchenham et al. [35,36]. The guidelines include planning the review, conducting the review, and documenting the review (Figure 1). Phase 1, the planning phase, involves four main processes: (1) justifying the need for a systematic review, (2) specifying the research questions, (3) developing the protocol, and (4) validating the protocol. Process 1 and 2 justify the importance of this review. Research questions will guide the next search process. Therefore, it is important to define stable and properly formulated research questions. The specific and valid research questions will guide the entire review process, including the primary study selection, data extraction, and data synthesis process. We identify the following research questions to guide this study: (RQ1) What IT is used in digital addiction research? (RQ2) 
How is IT used in digital addiction research? (RQ3) What are the research directions in the use of IT digital addiction research?

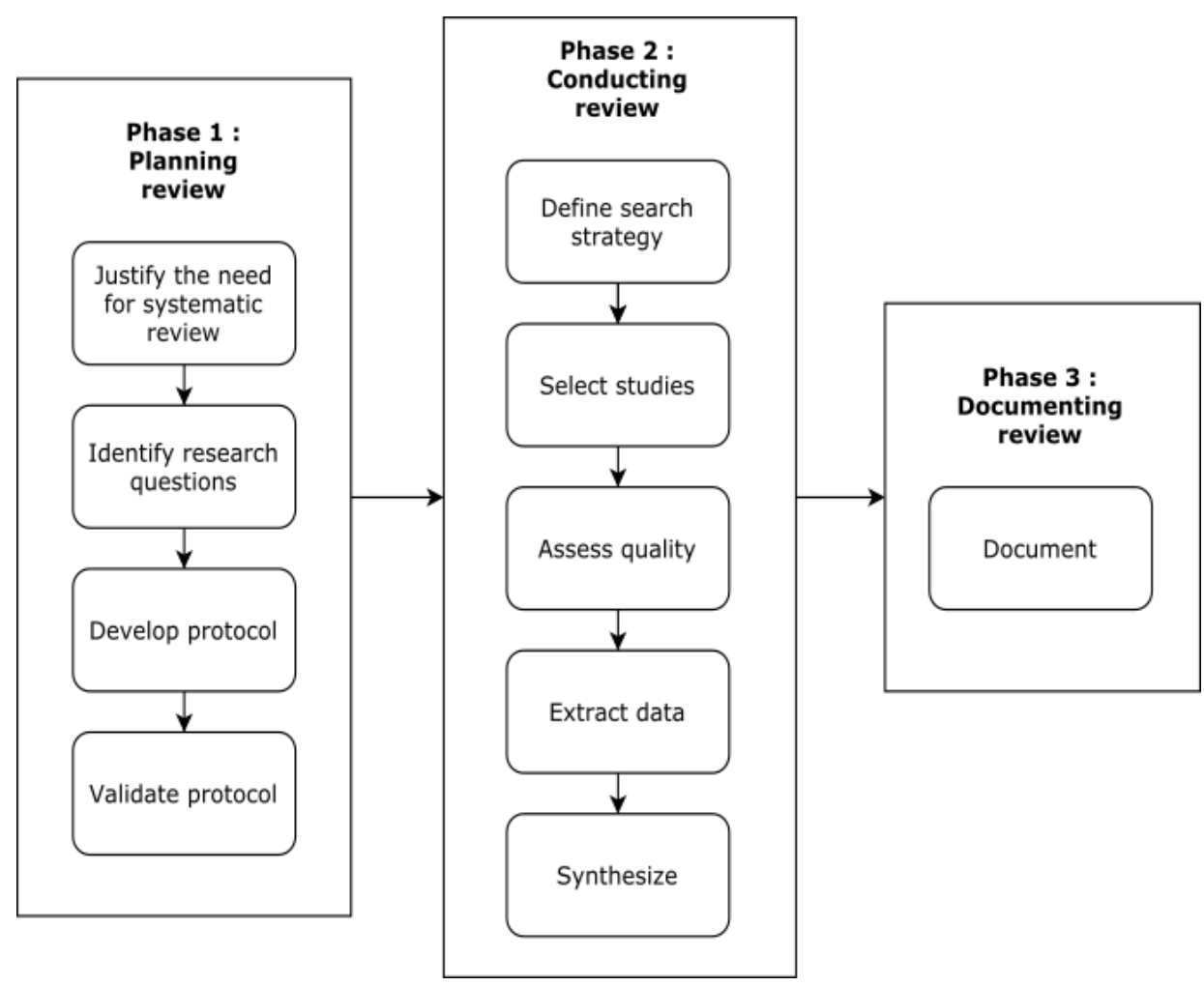

Figure 1. Review protocol (adapted from Kitchenham et al. [36]).

The technical processes used to conduct and report the review will be defined and justified in the research protocol. Phase 2, conducting review, consists of five processes. The first process is to define the search strategy. In the search strategy, we determined the search strings to find the appropriate studies. The search strategy was started with determining the basic scope, which includes the specific sources of studies and the search strings that will be used for an automated search on electronic data sources. We used the Scopus database as the database source. The search covered the literature published from 2017 until 2020. The literature search for papers published in 2020 was executed until 17 September 2020. Therefore, the results were obtained as of that date. The strings were searched in the article title, abstract, and keywords sections of the literature held in the Scopus database. This initial step in the search process resulted in the identification of 1655 papers. The search strings used are: "(TITLE-ABS-KEY ("online addiction" OR "internet addiction" OR "problematic internet use" OR "game addiction" OR "excessive internet use" OR "social media addiction" OR "social media attachment" OR "SNS addiction" OR "digital addiction" OR "smartphone addiction") AND TITLE-ABS-KEY ("detect" OR “detection" OR “diagnose" OR "diagnosing" OR "measure" OR "measurement" OR "prevent" OR "prevention" OR "intervene" OR "intervention" OR "combat" OR "treat" OR "treatment" OR “assess" OR "assessment" OR “test")) AND DOCTYPE (ar OR cp) AND PUBYEAR > 2016 AND PUBYEAR < 2021 "

The next step was to specify the selection criteria. We selected the primary studies based on the exclusion and inclusion criteria. The study selection criteria were then applied to exclude irrelevant studies. The exclusion criteria applied are as follows:

EC 1: Papers that are not related to the intended topic based on reading the title and abstract

EC 2: Duplicate studies and studies with similar topics and findings

EC 3: Comparison papers and review papers 
EC 4: Papers that are not relevant to the intended purpose of this study based on reading the paper content

In the first exclusion (EC1), we excluded papers that were not related to the use of technology in digital addiction by reading the abstract. This stage resulted in reducing the number of papers to 36. The second exclusion (EC2) was performed in which papers that belong to the same study and papers with similar themes and findings were removed for duplication. After applying these exclusions, 27 papers have remained. The third exclusion excluded One comparison paper and One review paper. There are 25 papers left from this exclusion. The fourth exclusion excluded papers that were considered irrelevant to the intended purpose of this study after a thorough reading of the papers' content. This process excluded two papers and resulted in 23 papers left.

The peer-review process was then conducted to validate the selection process. The 23 papers left were then screened by assessing its quality. We determine the quality criteria adopted from Uzun and Tekinerdogan [37] for assessing the quality of the papers. A dichotomous ("yes" or "no") scale was used to grade each of the criteria. Based on the assessment results and discussion between researchers, of the 23 articles assessed for quality, 8 papers were excluded. The remaining 15 papers (study A-O) were left for further extraction and synthesis. The overall literature search process is shown in Figure 2.

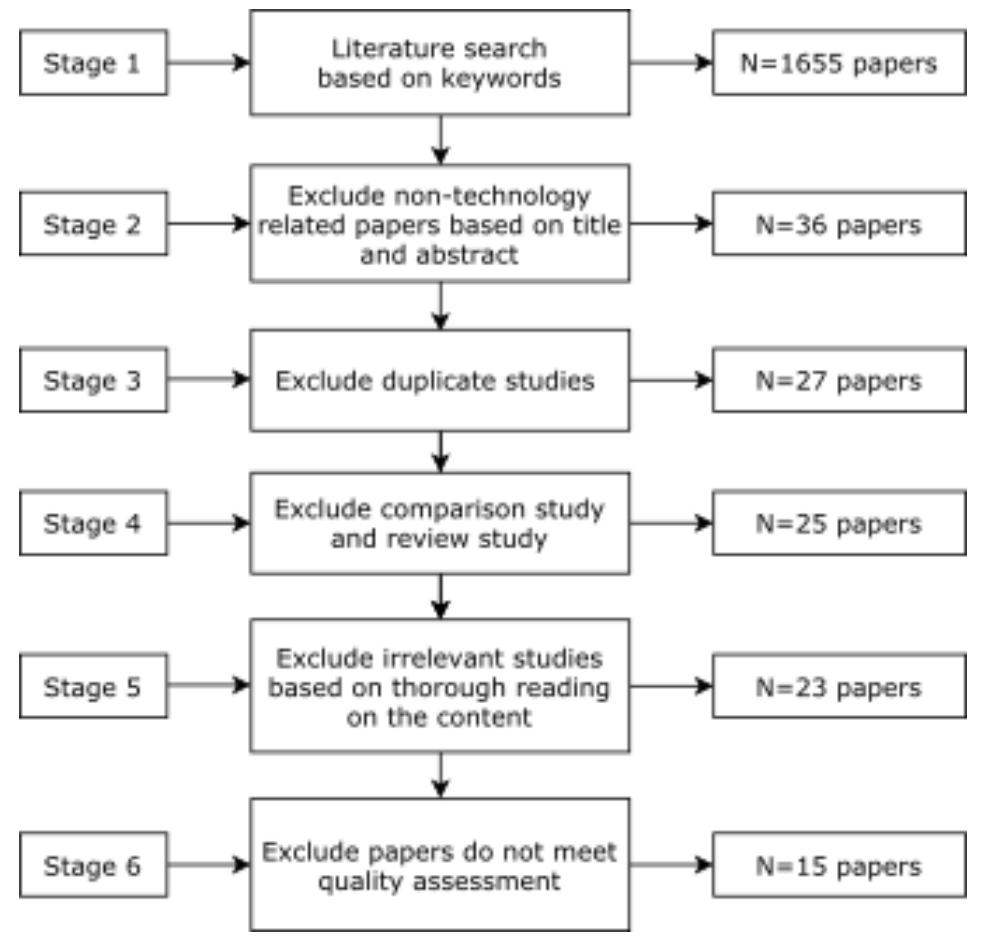

Figure 2. Stages of primary studies search.

Once the final studies were identified, the data were extracted from each of the 15 studies. All the information needed to answer the research questions were retrieved in the data extraction form. The data extraction form included a set of attributes such as identification number of the study, authors of the study, publication year, publication platform, publication type, country, the domain of the topic in digital addiction, research goal, the IT used or proposed in the study, research method, and findings. The data extracted from these 15 papers (study A-O) can be seen in Table 1 . The extracted data were then synthesized. In this stage, data extracted from primary studies were summarized and research questions were answered. We implemented a qualitative synthesis of the extracted data. The synthesis results are provided in the next section. 
Table 1. Selected studies on the use of IT in digital addiction research.

\begin{tabular}{|c|c|c|c|c|c|c|c|c|}
\hline Study ID & Year & Citation & Country & Category & Domain & Goal & Method & Findings \\
\hline A & 2017 & Choi et al. [38] & South Korea & Detection & $\begin{array}{l}\text { Smartphone } \\
\text { addiction }\end{array}$ & $\begin{array}{l}\text { To extract the usage patterns } \\
\text { related to smartphone } \\
\text { dependence and to use a } \\
\text { data-driven prediction algorithm } \\
\text { to predict } \\
\text { smartphone dependence }\end{array}$ & $\begin{array}{l}\text { Smartphone monitoring } \\
\text { application to collect } \\
\text { smartphone usage log data, } \\
\text { questionnaire-based assessment } \\
\text { to categorize subjects; tensor } \\
\text { factorization to derive usage } \\
\text { patterns; logistic regression to } \\
\text { predict addicted users }\end{array}$ & $\begin{array}{l}\text { The six usage patterns identified } \\
\text { were significant predictors of } \\
\text { smartphone dependence. } \\
\text { The usage patterns membership } \\
\text { vectors achieved better } \\
\text { prediction performance } \\
\text { compared to the raw data. }\end{array}$ \\
\hline B & 2017 & $\begin{array}{c}\text { Hafeez, Idrees, } \\
\text { and Kim [39] }\end{array}$ & South Korea & Detection & $\begin{array}{c}\text { Game } \\
\text { addiction }\end{array}$ & $\begin{array}{l}\text { To investigate the frequency } \\
\text { attributes of } \\
\text { electroencephalographs (EEGs) } \\
\text { for detecting the early signs of } \\
\text { game addiction and to design a } \\
\text { framework for alerting the user } \\
\text { about their potential } \\
\text { game addiction }\end{array}$ & $\begin{array}{l}\text { Questionnaire-based assessment } \\
\text { to categorize subjects; } \\
\text { experimental study to collect } \\
\text { EEG data; temporal and } \\
\text { frequency domain analysis and } \\
\text { logistic regression modeling to } \\
\text { analyze the EEG data }\end{array}$ & $\begin{array}{l}\text { The evidential proof to detect } \\
\text { game addiction was provided by } \\
\text { the parameterization of EEG } \\
\text { signals from the occipital region. } \\
\text { A device/application design for } \\
\text { game addiction detection was } \\
\text { proposed based on the results of } \\
\text { the examination of the frequency } \\
\text { attributes of EEGs. }\end{array}$ \\
\hline $\mathrm{C}$ & 2017 & $\begin{array}{l}\text { Wibirama \& } \\
\text { Nugroho [40] }\end{array}$ & Indonesia & Detection & $\begin{array}{l}\text { Smartphone } \\
\text { addiction }\end{array}$ & $\begin{array}{l}\text { To demonstrate the usage of } \\
\text { eye-tracking for observing the } \\
\text { screen size effect on the } \\
\text { immersion experience }\end{array}$ & $\begin{array}{l}\text { Experiment for data gathering; } \\
\text { Immersive Experience } \\
\text { Questionnaire (IEQ) to measure } \\
\text { the level of immersion }\end{array}$ & $\begin{array}{l}\text { The experience of immersion } \\
\text { was affected by screen size. } \\
\text { Fixational eye movements may } \\
\text { indicate the mobile } \\
\text { device addiction. }\end{array}$ \\
\hline $\mathrm{D}$ & 2018 & Kim et al. [41] & South Korea & Detection & $\begin{array}{c}\text { Game } \\
\text { addiction }\end{array}$ & $\begin{array}{l}\text { To detect a craving for gaming in } \\
\text { an individual with Internet } \\
\text { Gaming Disorder (IGD) using } \\
\text { multimodal } \\
\text { biosignal measurements }\end{array}$ & $\begin{array}{l}\text { Experiment to get PPG, GSR, } \\
\text { and EOG data, signal processing, } \\
\text { SVM to classify craving states, } \\
\text { statistical test to analyze results }\end{array}$ & $\begin{array}{l}\text { EOG is considered to be a } \\
\text { potential marker of the craving } \\
\text { state for individuals with IGD. }\end{array}$ \\
\hline E & 2018 & Yeo et al. [42] & South Korea & Detection & $\begin{array}{c}\text { Game } \\
\text { addiction }\end{array}$ & $\begin{array}{l}\text { To measure the heart rate (HR), } \\
\text { heart rate variability (HRV), } \\
\text { pulse transit time (PTT), and skin } \\
\text { temperature (SKT) data changes } \\
\text { in the resting state and the game } \\
\text { playing state using developed } \\
\text { biosignal measuring device }\end{array}$ & $\begin{array}{l}\text { Experiment for measuring } \\
\text { electrocardiogram, } \\
\text { photoplethysmogram, and skin } \\
\text { temperature data; statistical } \\
\text { analysis ( } t \text {-test \& Mann-Whitney } \\
\text { method) to analyze the } \\
\text { measurement results }\end{array}$ & $\begin{array}{c}\text { The pulse transit time, heart rate } \\
\text { variability, and skin temperature } \\
\text { showed increased the activities } \\
\text { of the sympathetic nerve during } \\
\text { gameplay, while the } \\
\text { parasympathetic nerves became } \\
\text { less active. }\end{array}$ \\
\hline
\end{tabular}


Table 1. Cont.

\begin{tabular}{|c|c|c|c|c|c|c|c|c|}
\hline Study ID & Year & Citation & Country & Category & Domain & Goal & Method & Findings \\
\hline $\mathrm{F}$ & 2019 & $\begin{array}{l}\text { Di, Gong, Shi, } \\
\text { Ahmed, } \\
\text { \& Nandi [43] }\end{array}$ & China & Detection & $\begin{array}{l}\text { Internet } \\
\text { addiction }\end{array}$ & $\begin{array}{l}\text { To examine the reliability of } \\
\text { machine learning methods in } \\
\text { detecting internet addiction }\end{array}$ & $\begin{array}{l}\text { Four questionnaire-based } \\
\text { assessments for dataset } \\
\text { acquisition; C-SVM, v-SVM, } \\
\text { and FNN for data classification }\end{array}$ & $\begin{array}{l}\text { The SVM proved to be a reliable } \\
\text { method to employ in } \\
\text { assessing IA. } \\
\text { The C-SVM, when applied to the } \\
\text { six-feature dataset without } \\
\text { normalization, had the best } \\
\text { detection performance ( } 96.32 \%) \text {. } \\
\text { Some potential features for IA } \\
\text { detection were identified. }\end{array}$ \\
\hline G & 2019 & $\begin{array}{l}\text { Hsieh, Shih, Shih, } \\
\text { \& Lin [44] }\end{array}$ & Taiwan & Detection & $\begin{array}{l}\text { Internet } \\
\text { addiction }\end{array}$ & $\begin{array}{l}\text { To propose a secure web } \\
\text { service-based ensemble classifier } \\
\text { with case-based reasoning } \\
\text { (EMBAR) system for classifying } \\
\text { users' internet addiction (IA) }\end{array}$ & $\begin{array}{l}\text { Questionnaire-based assessment } \\
\text { to determine subjects' addiction } \\
\text { level; temporary internet files } \\
\text { (TIFs) to identify internet usage } \\
\text { patterns; ensemble classifier to } \\
\text { classify subjects' addiction level; } \\
\text { CBR to make a final judgment }\end{array}$ & $\begin{array}{l}\text { The integration of ensemble } \\
\text { classifiers with CBR is } \\
\text { considered the best approach to } \\
\text { identify IA. The identification of } \\
\text { the level of IA by using the } \\
\text { ensemble classifier with CBR had } \\
\text { an average accuracy of } 89.9 \% \text {. }\end{array}$ \\
\hline $\mathrm{H}$ & 2019 & $\begin{array}{l}\text { Ji, Chen, } \\
\text { \& Hsiao [45] }\end{array}$ & Taiwan & Detection & $\begin{array}{l}\text { Internet } \\
\text { addiction }\end{array}$ & $\begin{array}{l}\text { To propose a reinforcement } \\
\text { learning system to determine } \\
\text { internet addiction (IA) }\end{array}$ & $\begin{array}{c}\text { Questionnaire-based } \\
\text { assessments to determine } \\
\text { subjects' addiction status; } \\
\text { experimental study to collect } \\
\text { subjects' respiratory } \\
\text { instantaneous frequency (IF) } \\
\text { data; XCSR to classify } \\
\text { subjects' IA }\end{array}$ & $\begin{array}{l}\text { XCSR was an effective learning } \\
\text { classifier system for detecting } \\
\text { high-risk IA (HIA) and } \\
\text { lower-risk IA (LIA). } \\
\text { The accuracy of classification by } \\
\text { XCSR can reach nearly } 100 \% \text { for } \\
\text { all data. }\end{array}$ \\
\hline I & 2019 & Noë et al. [46] & UK & Detection & $\begin{array}{l}\text { Smartphone } \\
\text { addiction }\end{array}$ & $\begin{array}{l}\text { To develop a new approach for } \\
\text { user activity monitoring by } \\
\text { using the physical interactions } \\
\text { between the user and the user } \\
\text { interface (UI) }\end{array}$ & $\begin{array}{l}\text { Bespoke monitoring application } \\
\text { to collect user interface } \\
\text { interaction events; } \\
\text { questionnaire-based assessment } \\
\text { to determine subjects' addiction } \\
\text { status; correlation analysis to } \\
\text { find the correlation between UI } \\
\text { interactions and } \\
\text { smartphone addiction }\end{array}$ & $\begin{array}{l}\text { The interaction events were not } \\
\text { significantly associated with } \\
\text { smartphone addiction when all } \\
\text { application data were considered. } \\
\text { The high levels of interaction } \\
\text { with lifestyle applications, } \\
\text { particularly among female users, } \\
\text { were significantly associated } \\
\text { with smartphone addiction. } \\
\text { Smartphone addiction correlated } \\
\text { with interactions in social } \\
\text { applications in general. } \\
\text { The Snapchat application was } \\
\text { correlated with smartphone } \\
\text { addiction in all interface } \\
\text { interaction types. }\end{array}$ \\
\hline
\end{tabular}


Table 1. Cont.

\begin{tabular}{|c|c|c|c|c|c|c|c|c|}
\hline Study ID & Year & Citation & Country & Category & Domain & Goal & Method & Findings \\
\hline $\mathrm{J}$ & 2018 & Chow et al. [47] & Hongkong & Prevention & $\begin{array}{l}\text { Smartphone } \\
\text { addiction }\end{array}$ & $\begin{array}{l}\text { To explore possibilities of } \\
\text { preventing excessive smartphone } \\
\text { use using a character-based } \\
\text { mobile application }\end{array}$ & $\begin{array}{l}\text { Field trial of using the } \\
\text { application; questionnaire to } \\
\text { survey the general usage of } \\
\text { smartphones; interview to get } \\
\text { participant's cognitive responses }\end{array}$ & $\begin{array}{l}\text { About half of the participants } \\
\text { associate imaginative } \\
\text { consequences to their behavior } \\
\text { of using phones. } \\
\text { Positive change behavior in } \\
\text { using phones was seen in } \\
\text { one-third of the participants. }\end{array}$ \\
\hline K & 2019 & Alrobai et al. [48] & UK & Intervention & $\begin{array}{c}\text { Digital } \\
\text { addiction }\end{array}$ & $\begin{array}{l}\text { To develop a reference model for } \\
\text { designing interactive online } \\
\text { platforms to host peer groups } \\
\text { and combat digital addiction and } \\
\text { to develop a process model to } \\
\text { build a customizable online } \\
\text { persuasive ecology (COPE) for } \\
\text { different groups }\end{array}$ & $\begin{array}{l}\text { Qualitative methods including } \\
\text { user studies and observational } \\
\text { studies }\end{array}$ & $\begin{array}{c}\text { A reference model for designing } \\
\text { interactive online platforms to } \\
\text { host peer groups and a process } \\
\text { model to build a COPE were } \\
\text { developed. }\end{array}$ \\
\hline $\mathrm{L}$ & 2020 & Aggarwal et al. [49] & India & Detection & $\begin{array}{l}\text { Game } \\
\text { addiction }\end{array}$ & $\begin{array}{l}\text { To predict the player's IGD } \\
\text { based on game and player } \\
\text { statistics }\end{array}$ & $\begin{array}{l}\text { Logistic Regression (LR), } \\
\text { KNearest Neighbor (KNN), } \\
\text { Naive Bayes (NB), Decision Tree } \\
\text { (DT), and Decision Tree with } \\
\text { Adaboost (DT-A) to predict IGD }\end{array}$ & $\begin{array}{l}\text { The Logistic Regression classifier } \\
\text { could predict IGD with a } \\
\text { maximum accuracy of } 93.18 \% \text {. A } \\
\text { strong positive correlation was } \\
\text { found between game statistics of } \\
\text { PUBG players and IGD }\end{array}$ \\
\hline M & 2020 & Liu et al. [50] & $\begin{array}{l}\text { New } \\
\text { Zealand }\end{array}$ & Intervention & $\begin{array}{l}\text { Internet } \\
\text { addiction }\end{array}$ & $\begin{array}{l}\text { To develop an AI-based recovery } \\
\text { framework for internet addiction }\end{array}$ & Literature analysis & $\begin{array}{l}\text { The AI-based recovery } \\
\text { framework that consists of three } \\
\text { key components was proposed }\end{array}$ \\
\hline $\mathrm{N}$ & 2020 & $\begin{array}{c}\text { Probierz \& } \\
\text { Galuszka [51] }\end{array}$ & Poland & Prevention & $\begin{array}{l}\text { Internet } \\
\text { addiction }\end{array}$ & $\begin{array}{l}\text { To propose the use of an expert } \\
\text { system to build a personalized } \\
\text { prevention program for a person } \\
\text { with PIU }\end{array}$ & $\begin{array}{l}\text { Questionnaire to obtain the data, } \\
\text { decision trees to determine the } \\
\text { prevention program }\end{array}$ & $\begin{array}{l}\text { The expert system that consists } \\
\text { of three decision trees was } \\
\text { proposed }\end{array}$ \\
\hline $\mathrm{O}$ & 2020 & $\begin{array}{c}\text { Sama \& } \\
\text { Kalvakolanu [52] }\end{array}$ & India & Detection & $\begin{array}{l}\text { Smartphone } \\
\text { addiction }\end{array}$ & $\begin{array}{l}\text { To assess the level of smartphone } \\
\text { addiction and find the } \\
\text { correlation between some } \\
\text { demographic data and } \\
\text { smartphone addiction }\end{array}$ & $\begin{array}{l}\text { The chi-square and Fisher's } \\
\text { exact test to test the hypotheses, } \\
\text { Fuzzy triangular method to } \\
\text { convert the addiction scores into } \\
\text { linguistic values }\end{array}$ & $\begin{array}{l}\text { A high percentage of } \\
\text { respondents with mild and } \\
\text { moderate levels of addiction was } \\
\text { found. } \\
\text { Gender, age groups, and years of } \\
\text { usage were associated with } \\
\text { smartphone addiction. } \\
\text { The "lack of control" and } \\
\text { "excessive use" dimensions } \\
\text { influenced the smartphone } \\
\text { addiction level. }\end{array}$ \\
\hline
\end{tabular}




\section{Results}

The second stage of the study selection process extracted 36 technology-related studies. These studies involve the use of IT in the digital addiction context. The number of papers distributed by year is shown in Figure 3. The highest number of papers on the use of IT in digital addiction is found in 2019. However, the number of papers published in 2020 may still increase since the literature search was only conducted until September 2020. Of the 36 papers found in the second stage, 26 papers are published in journals and 10 papers are published in conference proceedings. Figure 4 shows the journals where the 26 papers are published. From Figure 4, we can see that the research on digital addiction is conducted from various disciplines, such as psychology, medical, public health, and information technology.

Papers Distribution by Year

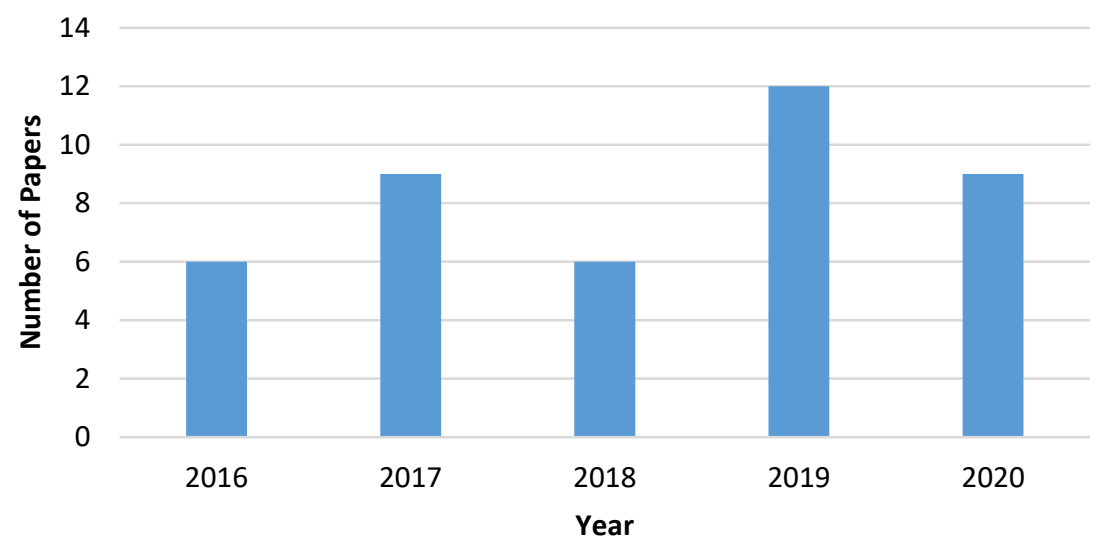

Figure 3. The number of papers published by year.

List of Publication Journals

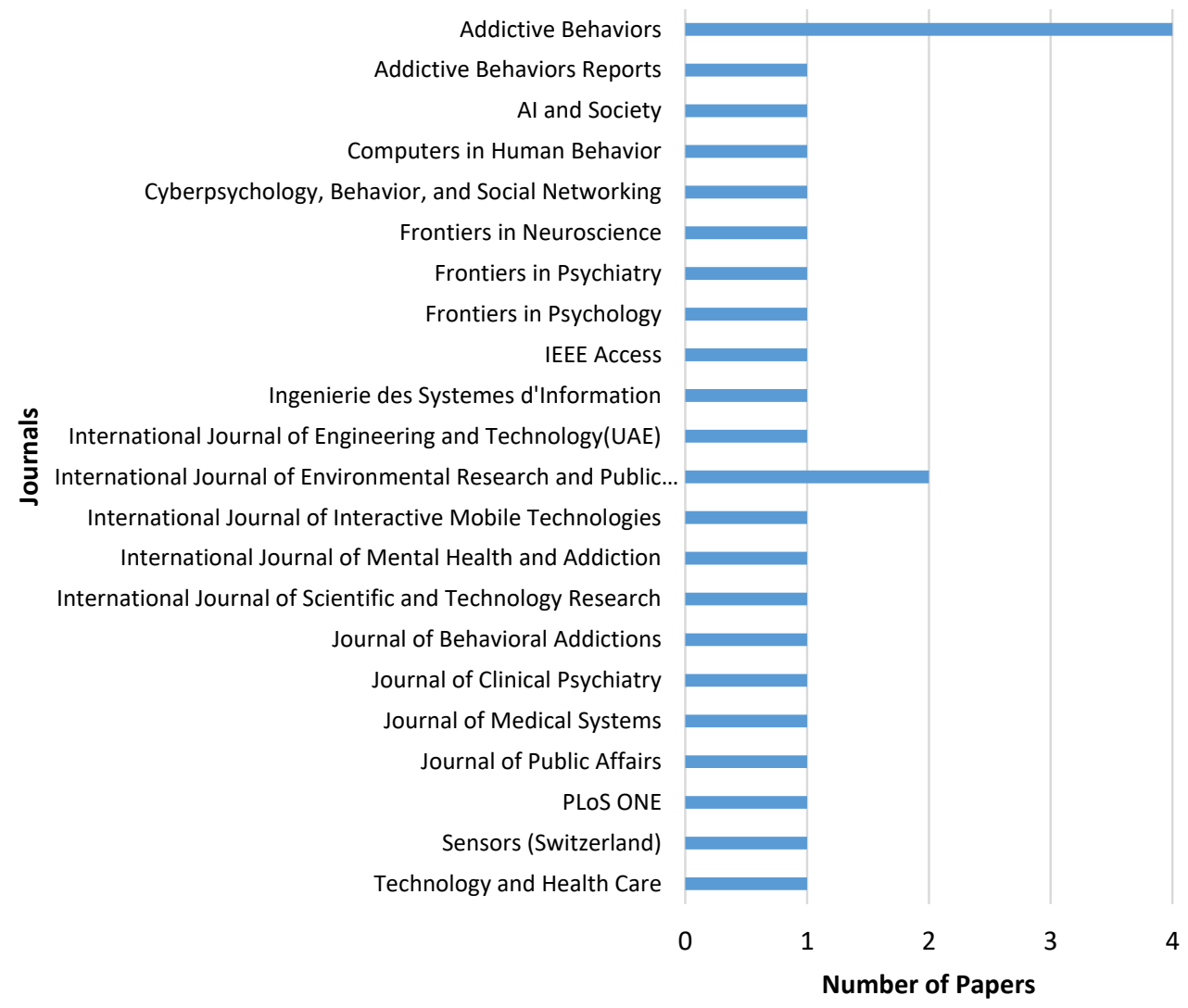

Figure 4. List of journals and publication numbers. 
From those 40 papers, we can classify the use of IT in digital addiction into three main purposes: (1) to detect/measure digital addiction, (2) to prevent digital addiction, and (3) to intervene in digital addiction. The number of papers in each category is shown in Figure 5, while the distribution of papers per year and per category are shown in Figure 6. The highest number of papers found is on detection effort. The research on detection is still a trend in digital addiction research, while the studies on prevention and intervention are less common. The studies were conducted in various addiction domains. We found 14 studies conducted in the internet addiction domain, 10 studies in the game addiction domain, 9 studies in the smartphone addiction domain, 1 study in the social media addiction domain, and 2 studies in the general context of digital addiction. The distribution of papers by its domain is shown in Figure 7.

Papers Distribution by Year

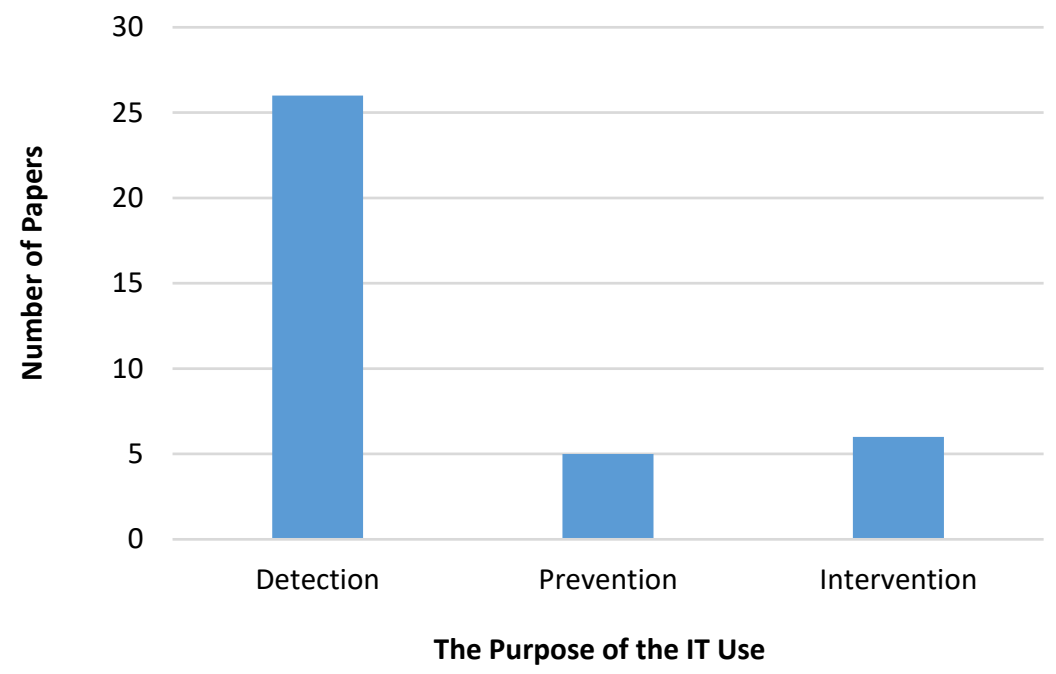

Figure 5. The number of studies in each purpose.

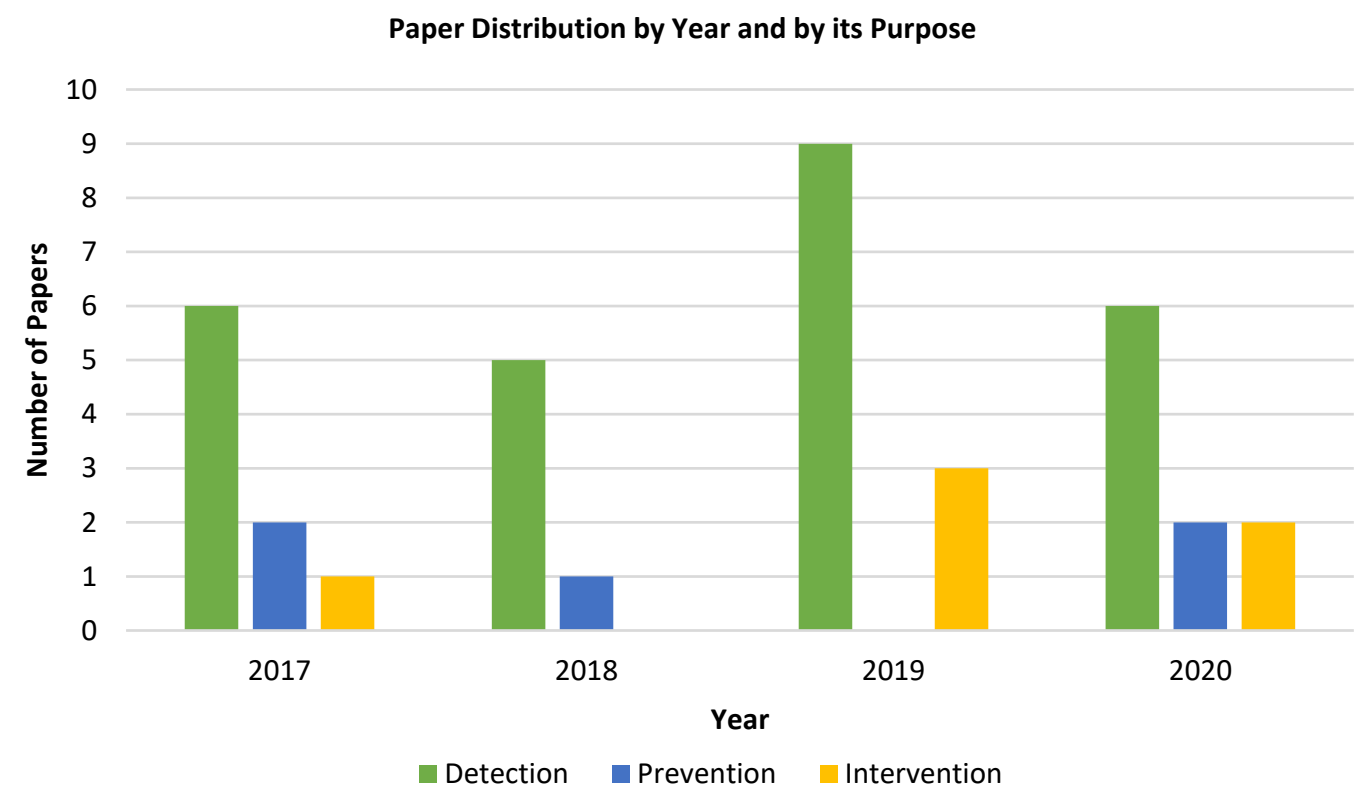

Figure 6. The distribution of studies by year and category. 


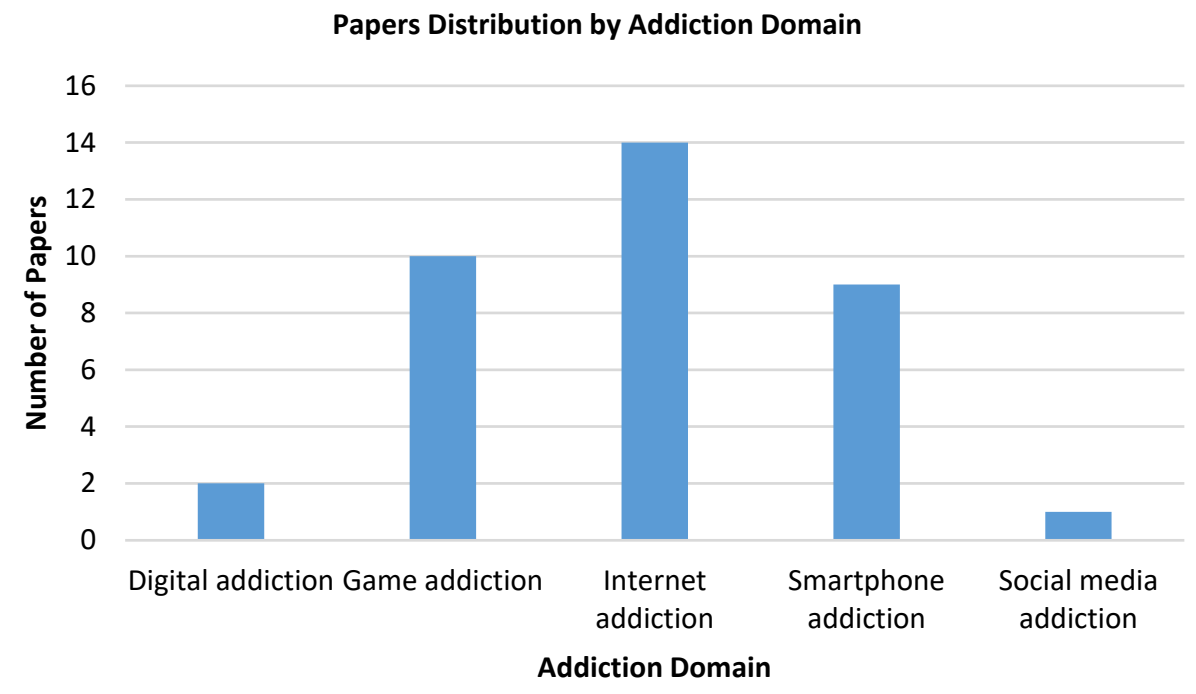

Figure 7. The distribution of studies by addiction domain.

After four stages of exclusions and quality assessment, we found 15 final papers to be synthesized. Information from the extracted studies are shown in Table 1. Following is the overview of the extracted studies

\section{Studies}

\subsection{Study A}

This study attempted to predict smartphone dependence based on users' usage patterns. The usage patterns from log data were collected by using a smartphone usage monitoring application. After conducting an assessment using the Korean Smartphone Addiction Proneness Scale for Adults (S-Scale) and an offline interview, the users were classified into two groups: an addiction group and a control group. The events collected from log data were represented by using tensor factorization and classified into six patterns: web surfing, social networking services (SNS) during the daytime, mobile shopping, SNS at night, gaming at night, and entertainment. Logistic regression was used to predict whether an event was generated by an addicted user. This study used membership vectors as the feature set for the prediction model. The result showed that the membership vectors of the usage patterns gave a better prediction performance than the raw data. The findings proved that usage data can be used to predict smartphone addiction and therefore can be used to provide a guideline for efforts to predict and treat smartphone dependence.

\subsection{Study B}

This study examined the effectiveness of using electroencephalography (EEG) frequency attributes to detect the markers of game addiction and attempted to design a system for alerting the user to their potential game addiction based on EEG results. In the first part of the study, a questionnaire-based assessment was performed to categorize the subjects into normal or problematic game players. Then, electroencephalographic data were recorded during mobile game playing. The EEG data were then analyzed to distinguish between addicted and nonaddicted game players. The finding showed that the EEG signal parameterization from the occipital region was the best option for detecting game addiction. The second part of the study involved the design of a wearable mobile addiction sensing system. This system consisted of a wearable headset to detect occipital region signals and a smart device to receive EEG signals from the wearable headset. The signals received were then analyzed to make an alert or recommendation based on the results of the EEG analysis. 


\subsection{Study C}

This study investigated the use of eye-tracking for observing the effect of screen size on the experience of immersion. Immersion has been considered as a significant predictor of video game addiction. The real-time eye movement data were collected during game playing on various sizes of touch screen devices. These data were then compared with the questionnaire results. The questionnaire used for measuring the immersion level was the Immersive Experience Questionnaire (IEQ). An analysis of immersion showed that the more significant experience of immersion was gained from a mobile device with a big screen size than a mobile device with a small screen size. Statistical analysis also showed that amount of fixation during game playing on a mobile device with a big screen size was less than the amount of fixation during game playing on a mobile device with a small screen size. This study suggested that fixational eye movements may indicate a mobile device addiction.

\subsection{Study D}

This study investigated the detection of craving for gaming in individuals with IGD using multimodal biosignal measurements. The individual's craving was assessed with a self-report craving score. The photoplethysmogram (PPG), galvanic skin response (GSR), and the electrooculogram (EOG) signals were recorded to observe the subsequent changes in biosignals recorded during gameplay. The signals recorded were then analyzed using a support vector machine (SVM) for classifying the individual craving states. This study found significant decreases in the standard deviation of the heart rate, saccadic eye movements, the number of eye blinks, and a significant increase in the mean respiratory rate. EOG is considered as a potential indicator of the individual craving state than the other biosignals adopted in this study.

\subsection{Study E}

This study aimed to measure the change of heart rate (HR), heart rate variability (HRV), pulse transit time (PTT), and skin temperature (SKT) data in individuals with IGD. The measurement was done during the experiment using a developed wearable device to measure electrocardiogram, photoplethysmogram, and skin temperature. The Mann-Whitney method was used to analyze the biosignal's changes from the resting state to the game-playing state. The results showed that there were increasing sympathetic nerve activities on the heart rate variability, pulse transit time, and skin temperature during gameplay, while the parasympathetic nerves became less active.

\subsection{Study F}

This study used machine learning techniques, namely, the support vector machine (SVM) and the fuzzy neural network (FNN) to assess internet addiction. The dataset was acquired from four questionnaires, namely, the Brief Self Control Scale (BSCS), the Chinese Big Five Personality Inventory (CBF-PI), the 11th version of the Barratt Impulsiveness Scale (BIS-11), and the Chen Internet Addiction Scale (CIAS). This study employed five datasets to test and compare the performance of SVM, C-SVM, $v$-SVM, and FNN with or without grid search. The results showed that SVM was a reliable method for internet addiction assessment and questionnaire data analysis. The best performance in internet addiction detection was $96.32 \%$, which was achieved by C-SVM when applied to the six-feature dataset without normalization. The results also showed that the BIS-11, BSCS, Motor, Neuroticism, Nonplanning, and Conscientiousness were promising features for internet addiction detection.

\subsection{Study $G$}

This study proposed a web service-based ensemble classifier with case-based reasoning (EMBAR) system to predict internet addiction. This study used a dataset of user profiles, which was created from users' internet addiction test questionnaires and temporary internet files (TIFs). A self-organizing map was then used to cluster the dataset. This step was followed by the extraction of users' internet behavior. 
An ensemble classifier was then used to classify the users' addiction levels. The ensemble classifier that was used contained four general-purpose classifiers: an SVM, Bayesian network classifier, decision tree (C5.0), and k-nearest neighbor. Case-based reasoning (CBR) was used to make a final judgment on the users' internet addiction levels. The empirical results showed that the EMBAR system offered better performance than the other classifiers, where the accuracy of internet addiction identification for mild, moderate, and severe addiction was $86.3 \%, 84.9 \%$, and $98.6 \%$, respectively.

\subsection{Study $H$}

This study proposed the real-time detection of internet addiction by using a reinforcement learning (RL) system. This study was proposed to overcome the drawbacks of using traditional addiction detection questionnaires for real-time discrimination. This study used the extended classifier system with continuous real-coded variables (XCSR) and an RL system. Participants' internet addiction was first assessed by using CIAS. Then experimental procedures were conducted to get respiratory data from the participants. The CIAS results and users' respiratory instantaneous frequency (IF) components were then processed using XCSR. The result showed that the accuracy of classification using XCSR can reach around $100 \%$. In this study, XCSR was also used to verify the CIAS items and to obtain important respiratory indexes to assess internet addiction.

\subsection{Study I}

This study proposed an approach to predict smartphone addiction using physical interactions between the user and the application interface. The users' addiction level was measured by using a Smartphone Addiction Scale (SAS). The study involved monitoring the interaction events of 64 participants over eight weeks. These interaction events included tapping, scrolling, and typing, which were recorded by using a bespoke monitoring application. Participants' usage behavior was then analyzed by comparing the number of events between participants. This study also examined a wide range of applications and compared different applications and classes of application. The result showed that the interaction events were not significantly associated with smartphone addiction when all application data were considered. However, the high levels of interaction in lifestyle applications were significantly correlated with smartphone addiction, particularly in female users. High-level interactions with social applications were also correlated with smartphone addiction in both male and female users. Furthermore, all types of interface interaction in the Snapchat application correlated with smartphone addiction.

\subsection{Study J}

This study used a character-based mobile application to stimulate users' imagination of the behavioral consequences and reflection on the behavior to prevent adolescents or young adults from excessive use of smartphones. The application design aims to make users able to relate the effects on the character with their excessive use of smartphones. Automated logging was used to track each participant's usage. In-depth interviews were used to examine cognitive responses. The analyzed interview data were compared with logged data. The result showed that about half of the participants associate imaginative consequences to their behavior of using phones. Positive change behavior in using phones was seen in one-third of the participants. This research suggested that the association of physical acts with virtual consequences could correlate with behavior change.

\subsection{Study K}

The purpose of this study was to examine how to facilitate the design process to develop an online peer group to combat digital addiction. Several qualitative methods were used including user studies and observational studies. Some observational studies were done to develop outputs. Those outputs are a reference architecture, a set of design artifacts, and a customizable online persuasive ecology (COPE.er) method. A case study was then undertaken to apply those outputs in practice. This study 
produced two primary outcomes. The first was a reference model for designing interactive online platforms to host peer groups and combat digital addiction. The second was a process model, COPE.er, that could be used to build a customizable online persuasive ecology.

\subsection{Study L}

This study aims to predict whether the player of PlayerUnknown's Battlegrounds (PUBG) game suffers from Internet IGD and two other psychological disorders, namely Attention Deficit Hyperactivity Disorder (ADHD) and Generalized Anxiety Disorder (GAD). This study used the PUBG game and player statistics and processed it with several supervised machine learning models, such as Logistic Regression (LR), KNearest Neighbor (KNN), Naive Bayes (NB), Decision Tree (DT), and Decision Tree with Adaboost (DT-A) to predict the occurrence of IGD, ADHD, and GAD. The results showed that the Logistic Regression classifier could predict IGD with a maximum accuracy of $93.18 \%$. This study found a strong positive correlation between game statistics of PUBG players and IGD.

\subsection{Study $M$}

This study describes the main challenges of using the internet to cure internet addiction and proposes a framework to develop an AI-based recovery system. The framework consists of three key smart components, namely: IA self-assessment, monitoring and AI learning, and stepped intervention strategies and response. The IA self-assessment or screening process using a questionnaire is conducted to get the user's daily internet use. The AI would identify if there is a discrepancy between the actual use and the expected use of the internet. If the discrepancy was detected, the user will be invited to join the IA recovery program. The AI monitoring and learning process plays a role in observing and learning the user's usage behavior to conduct the corresponding interventions. Based on the results of the IA self-assessment and AI monitoring and learning process, this framework proposes some AI-based intervention strategies, including self-governance, peer-assisted, and AI-assisted and AI-enforced intervention.

\subsection{Study N}

This study proposed an expert system to build a prevention program for persons with problematic internet use (PIU). The expert system proposed consists of three decision trees. The first tree was used to classify the person's PIU risk level. The second tree was used to determine the proper duration of the prevention program, and the third One was applied to determine the type of prevention program that best matches the person's PIU risk level. The prevention programs consist of three specialist programs and One general program. The specialized programs include social and communication skill programs, emotion and affect programs, and time control and procrastination programs.

\subsection{Study O}

This study assesses the level of smartphone addiction using fuzzy and statistical analysis approaches. The data obtained from the Smartphone Addiction Test (SAT) were treated using a fuzzy operator and the statistical techniques applied to analyze the relationships between the respondent's demographic data and the levels of smartphone addiction. This study applied a triangular fuzzy approach for finding the dimension that most influenced smartphone addiction. The study found a high percentage of respondents with mild and moderate levels of addiction. Some demographic data such as gender, age groups, and years of usage were associated with smartphone addiction. The critical dimensions of smartphone addiction measurement, namely "lack of control" and "excessive use", were found to be the two highest influencers of smartphone addiction level.

\section{Discussion}

Digital addiction is a multifaceted problem. Therefore, it is significant to have a comprehensive understanding of this phenomenon to overcome its adverse impacts. Several factors contribute to 
the onset of addiction, including IT. We argue that IT as One of the factors that contribute to the development of addiction can also have a contribution to the effort of combating digital addiction. The present study attempts to examine what other researchers have been done so far in exploring the positive role of IT in digital addiction research. This section provides the answer to each question specified in the methodology section.

This present study has extracted 15 papers that meet predefined criteria as seen in Table 1. These 15 studies show various IT used for combating digital addiction. A previous review study on e-health intervention for problematic internet use conducted in 2016 only found three papers that meet prespecified criteria [30]. The IT used for intervention in those three papers are an online expert system [53], application [54], and virtual reality [28]. The selected papers from this present study show more various IT use. The IT used in the extracted studies can be classified into four groups. Those are mobile applications, frameworks, AI methods, and biosignal recording systems. The number of studies and the IT used in those studies is shown in Figure 8. This study finds that $\mathrm{AI}$ and biosignal recording systems are the two most commonly used IT in digital addiction research. The advantages of AI have also been extensively explored in healthcare, such as to obtain insights for assisting clinical practice, to reduce diagnostic and therapeutic errors in the clinical practice, to predict health outcomes, and to assist in making health risk alerts [55]. Study D, F, G, H, L, N, and O leveraged the advantages of AI to design more reliable digital addiction detection systems. The AI methods used include logistic regression, k-nearest neighbor, naive bayes, decision tree, support vector machine, fuzzy neural network, fuzzy triangular, and extended classifier. Those various methods function as a smart processing machine to find the pattern of addiction or classify the level of addiction from various data sources. Those studies lay the groundwork for the further development of digital addiction detection systems using AI.

Papers Distribution by IT Category

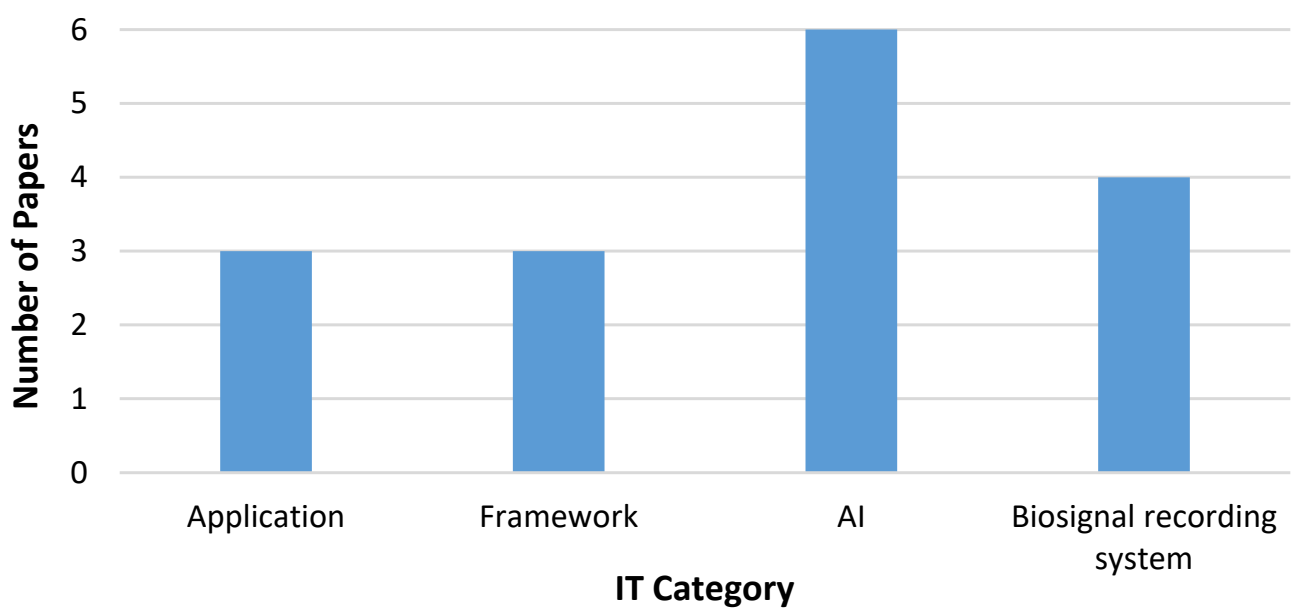

Figure 8. The number of studies and the IT used.

The biosignal has been extensively used in detecting health problems due to its ability to provide real-time state of the biological system change. While the AI methods act as a processing machine to analyze the data, the biosignal recording systems are used to collect human physiological data for further analysis. The purpose of utilizing physiological parameters is to get real-time and more reliable data for detecting digital addiction that cannot be obtained from traditional assessment tools. Some physiological parameters recorded are brain signal, heart rate, heart rate variability, eye blink, eye movement, respiratory rate, respiratory index, and skin conductance response.

Internet and game addiction can lead to neuroadaptation and structural changes in the brain [56]. The marker of game addiction can be observed from particular areas of the brain, such as the occipital, parietal, temporal, and frontal lobes [57,58]. However, study B found that the distinctive pattern of addiction was found in the occipital region of the brain. Thus, the study suggested that the signals 
from the occipital region can provide evidential proof to identify game addiction. The involvement of the cardiorespiratory system has also been studied to find the indicator of addiction. The analysis of pulse transit time, heart rate variability, and skin temperature showed increased sympathetic nerve activities during a computer game, while the parasympathetic nerves became less active (study E). The activation of the sympathetic nervous system was also found when participants were in the craving for gaming conditions (study D). Some particular respiratory instantaneous frequencies were suggested as addiction indicators (study $\mathrm{H}$ ). The involvement of physiological parameters from the human eye in digital addiction, such as eye blinks and eye movements, was also investigated. The number of eye blinks and the distance of the saccadic eye movements were found significantly decreased during the gameplay (study D). These conditions may occur due to increased attention during gaming [41].

The applications found in study A and study I are used to collect the user activities to be saved in a log file. These mobile applications are operated in the background. The user behavior data from a $\log$ file are then analyzed with various techniques to assess or detect smartphone addiction. In study A, the log data are represented by tensor factorization to later be used to predict smartphone addiction. Study I use log data to record user interaction events in using a smartphone to predict user's smartphone addiction. Different from previous studies, study J uses a mobile application not to create a log file but to stimulate user imagination and reflection on their smartphone usage behavior. The character generated from a mobile application can respond to user usage behavior that reflects the consequences of excessive smartphone use.

Three studies develop a framework to guide the development of systems to detect or intervene in digital addiction. Study B proposes a framework to design a wearable mobile addiction sensing system that aimed to detect game addiction. The system proposed may be used as a user personal assistant or as a resource to suggest better rehabilitation by any specialist. Study K proposes a reference model and a process model to design interactive online platforms to host peer groups for a digital addiction intervention. Study M proposed an AI-based recovery framework for internet addiction. Those three studies guide future research in developing digital addiction intervention solutions. The IT used/proposed and its function are shown in Table 2.

The use of IT in digital addiction has three main purposes, namely to detect/measure digital addiction, to prevent digital addiction, and to intervene in digital addiction. In the detection effort, the detection approaches used can be classified into three groups. The first approach is by examining physiological parameters from various human biosignals to find the particular physiological parameter that may be the indicator of addiction. This approach is conducted to overcome the authenticity problem of questionnaire-based digital addiction detection instruments (i.e., the Internet Addiction Scale (IAS), CIAS, and SAS). Biosignals carry information about the state of the biological system [59]. Therefore, the strength of this approach relies on the reliability of human biosignal data that manifests as a response to a particular stimulus. However, the assessment utilizing biosignals requires a particular recording device that may be impractical to implement, particularly if it will be implemented as a personal monitoring device for an individual with digital addiction. EEG or fMRI devices, for instance, have been typically used to record the brain signals, but it may be impractical or improper to use it for assisting an individual in his daily life.

The second approach is to detect digital addiction symptoms by analyzing user's usage behavior. The advantage of this approach lies in the easiness of collecting the data. The user behavior data can be obtained from a log file, temporary internet file, or application programming interface (API). However, this approach may take some time to obtain the intended usage behavior. The amount of data obtained may also influence the findings. Thus, this approach may not be suitable for real-time detection. Furthermore, the usage behavior derived from usage time may not represent the strongest indicator of smartphone addiction [46]. 
Table 2. The IT used/proposed and its function.

\begin{tabular}{|c|c|c|c|}
\hline Study & IT Used/Proposed & IT Function & IT Category \\
\hline A & Mobile application & $\begin{array}{l}\text { Record the user's behavior from a log file for further } \\
\text { analysis in smartphone addiction prediction }\end{array}$ & Application \\
\hline $\mathrm{B}$ & $\begin{array}{ll}\text { - } & \text { Device/application framework } \\
\text { - } & \text { EEG recording system }\end{array}$ & $\begin{array}{l}\text { - Alert users about their potential game addiction } \\
\text { - Record the user's electroencephalographic data to } \\
\text { detect the markers of game addiction }\end{array}$ & $\begin{array}{ll}- & \text { Framework } \\
\text { - } & \text { Biosignal recording system }\end{array}$ \\
\hline $\mathrm{C}$ & Eye tracker & $\begin{array}{l}\text { Track eye movements to observe the experience } \\
\text { of immersion }\end{array}$ & Biosignal recording system \\
\hline $\mathrm{D}$ & $\begin{array}{l}\text { - } \quad \text { PPG, GSR, and EOG recording system } \\
\text { - } \quad \text { Support Vector Machine }\end{array}$ & $\begin{array}{l}\text { - } \quad \text { Record GSR, PPG, and EOG signals to detect craving } \\
\text { for gaming } \\
\text { - } \quad \text { Classify the individual craving states }\end{array}$ & $\begin{array}{ll}\text { - } & \text { Biosignal recording system } \\
\text { - } & \text { AI Method }\end{array}$ \\
\hline $\mathrm{E}$ & ECG, PPG, and skin temperature wearable device & $\begin{array}{l}\text { Record ECG, PPG, and skin temperature signals to } \\
\text { examine the changes of these biosignals during gameplay }\end{array}$ & Biosignal recording system \\
\hline $\mathrm{F}$ & Support Vector Machine and Fuzzy Neural Network & Classify user's internet addiction & AI method \\
\hline G & $\begin{array}{l}\text { A web service-based ensemble classifier with } \\
\text { case-based reasoning (EMBAR) system }\end{array}$ & Classify the user's internet addiction level & AI method \\
\hline $\mathrm{H}$ & $\begin{array}{l}\text { eXtended Classifier System with Continuous } \\
\text { Real-Coded Variables (XCSR) }\end{array}$ & Classify user's internet addiction & AI method \\
\hline I & A bespoke monitoring application & $\begin{array}{l}\text { Record user interaction with smartphone applications } \\
\text { Poll the screen status (i.e., on or off) of the user's }\end{array}$ & Application \\
\hline $\mathrm{J}$ & A character-based mobile application & $\begin{array}{c}\text { smartphone and generate an animated character with } \\
\text { different states }\end{array}$ & Application \\
\hline K & A reference model and a process model, COPE.er & $\begin{array}{c}\text { Guide the process of designing interactive online } \\
\text { platforms and building a customizable online } \\
\text { persuasive ecology }\end{array}$ & Framework \\
\hline $\mathrm{L}$ & Several supervised machine learning methods & Predict the occurrence of IGD & AI method \\
\hline M & $\begin{array}{l}\text { A framework to develop an AI-based } \\
\text { recovery system }\end{array}$ & Guide the development of AI-based recovery system & Framework \\
\hline $\mathrm{N}$ & Expert system with decision trees & $\begin{array}{l}\text { Classify user's PIU risk level, determine the duration of } \\
\text { the prevention program, and determine the type of } \\
\text { prevention program }\end{array}$ & AI method \\
\hline $\mathrm{O}$ & Fuzzy triangular approach & $\begin{array}{c}\text { Find the most influencing dimension of } \\
\text { smartphone addiction }\end{array}$ & AI method \\
\hline
\end{tabular}


The third approach is by using a self-assessment survey. The survey results in the third approach are then analyzed with particular methods to detect addiction. The self-assessment survey method, such as the questionnaire, has One main advantage that is the data collection is relatively easy to do. However, this method also has some drawbacks. Because the questionnaire relies on participant's perception, it may lack authenticity. The other drawback is it needs an adequate number of participants that sufficiently represent the population. This approach is usually applied to test or compare the best methods for detecting addiction. Thus, the strength of this approach does not lie in the data collection method but may depend on the processing method used.

The advantages and limitations of the detection system approach are shown in Table 3.

Table 3. The advantage and limitation of the detection system approach.

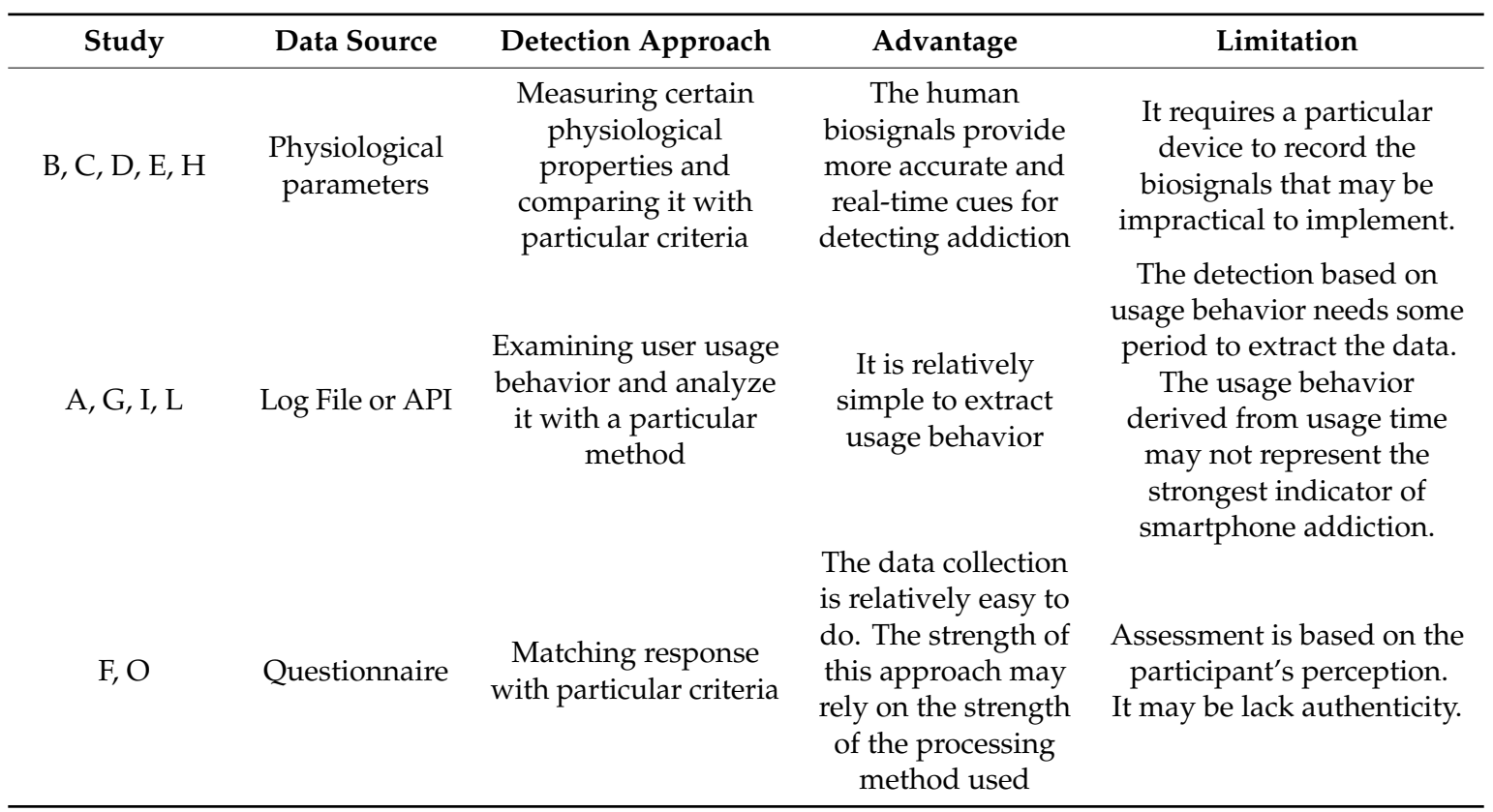

For prevention, there are two approaches used in the study. The first approach is by utilizing application features to raise user awareness. Study A aims to raise user awareness of the consequences of smartphone excessive use using virtual characters. The generated characters will respond to the user's actions by showing particular emotions that reflect the consequences of user actions. The strength of this approach may lie in the grounded theory that is used to design the features. The application design in study A is grounded in social psychology and embodied cognition theory, including feedback interventions, conceptual metaphor and blending, the concept of animacy, and liveliness. This approach measures the normality of smartphone use based on usage time. However, the time spent on a smartphone is not necessarily the signal of addictive behavior [60].

The second approach in prevention is by utilizing AI to determine the addiction risk level and select the best prevention program for the user (study N). The advantage of this approach is it can provide an appropriate prevention program based on the user's addiction risk level. Because this approach uses the expert system, the reliability of the results depends on the reliability of the knowledge base and the inference engine used. However, this approach only uses psychopathologies, i.e., depression, stress, and anxiety as parameters to classify the addiction risk level. The classification misses some other significant factors, such as environmental-level factors that contribute to the onset of addiction [20]. The role of AI in this study is only as a means for selecting the proper prevention program, but $\mathrm{AI}$ is not involved in the prevention program itself.

In the intervention effort, all studies found propose frameworks to develop intervention systems. Because the approach found in intervention studies is by proposing frameworks, the strength of this approach lies in the grounding theories used to develop the frameworks. The first study (study K) uses 
a peer-group approach to digital addiction intervention. Peer-groups are classified as support therapy that involves other individuals (counselor, family, and friends) to give social and emotional support to an individual with digital addiction [48]. This approach is grounded in some psychological theories, including self-psychology, cognitive consistency theory, helper therapy principle, social learning theory, and group psychotherapy.

The second study in digital addiction intervention (study $\mathrm{M}$ ) utilizes the advantages of AI to closely monitor and analyze user's internet usage behavior for recommending possible staged intervention. The use of the internet in internet addiction intervention is challenging since the internet itself is considered as the means of addiction. In study M, the AI approach is suggested to tackle some challenges in the development of internet-based intervention systems, namely the complexity of internet addiction diagnosis, the extensive use of ubiquitous devices, and workaholic behaviors. The framework consists of self-assessment, monitoring and AI learning, and various intervention strategies and responses features. However, this study does not provide the theoretical background of the intervention strategy proposed. Because the two studies in the intervention are only focused on the development of the framework, the effectiveness of the intervention strategies proposed cannot be measured yet.

Based on the analysis of the extracted studies, two main research directions in the use of IT to combat digital addiction are proposed. First, the utilization of IT for digital addiction prevention and intervention with various approaches may be further investigated in the future. As seen in Figure 5, we find fewer studies in the prevention and intervention efforts. Most studies found are still focused on the detection effort using various approaches. Accurate detection results are the significant input required to determine the proper intervention strategy. Thus, researchers may still seek the most effective approach in digital addiction detection. Therefore, we find most studies are done in this domain. However, up to this date, no study presents what is the best approach in digital addiction detection. In the prevention domain, another review study also finds that the literature is scarce [61]. Most of the previous studies [62-65] on the prevention of digital addiction are done in the school environment with the various psychoeducational programs. However, there is a lack of study that utilizes IT to carry out those programs. Therefore, future research on prevention may wish to focus on IT utilization in the implementation of psychoeducational programs. The prevention approach by stimulating user awareness as suggested in study A is One of the psychological approaches in addiction prevention. However, it is still limited in that it only uses the time dimension as a basis for providing prevention feedback to users. Future research may enhance the advantage of this approach by involving some other dimensions. The second study found in prevention proposed the utilization of AI to suggest the appropriate prevention program for users. However, in this study, AI only plays a role in selecting the proper prevention program based on the individual's addiction risk level. AI has the potential to be explored as an essential part of the prevention program itself. For instance, using the approach applied in study A, the process of stimulating user awareness can be implemented by utilizing AI. All studies found on the intervention propose frameworks to develop IT-based intervention programs. Because the results of these studies are still in the conceptual stage, future research may focus on the implementation of these frameworks and the measurement of the intervention strategy's effectiveness for combating digital addiction.

Second, the utilization of human physiological parameters and AI technology may still be further explored for developing an effective, reliable, and real-time system for combating digital addiction. The IT found in this study can be classified into four categories, i.e., application, application framework, AI, and biosignal recording system. The two most used IT in the selected studies are AI and biosignal recording system (Figure 8). The biosignal recording system has strength in recording real-time human physiological data. The real-time detection system may be used further by users to assist them in using digital technology or may be used by any specialists in the user rehabilitation effort. One consideration in developing a physiological-based detection system is how it can be implemented as a personal device that can be used practically by users at an affordable cost. Future research may explore the 
development of such technology. The strength of AI lies in its capability to intelligently process the input data. The intelligent system can be developed to assist users to prevent or intervene in excessive behavior of using digital technology. This intelligent system may exploit various AI technologies as its processing system. The potential capabilities of AI have also been studied and implemented in the other addiction domain, i.e., substance addiction domain. Various AI technologies have been implemented in the prevention and intervention of substance addiction [66]. One example of AI applications that help those suffering from substance addiction is Addicaid. Addicaid combines machine learning, adaptive AI, and clinical research to predict when a person may be at risk for relapse and generate treatment suggestions [67]. The other app called Triggr was developed to provide moral support during someone's recovery. Triggr has capabilities to track how long a person has been sober and to connect him via text message or chatting apps with his recovery coaches [66]. Considering each of the advantages of biosignal recording systems and AI, future research may wish to focus on combining the strength of those IT to develop a reliable and real-time system for detecting and combating digital addiction.

\section{Conclusions}

The present study attempts to explore the state of play and the trend on IT use in digital addiction research. By following a systematic literature review methodology, we found 15 studies that met a predefined set of inclusion criteria. The main purposes of the use of IT in selected studies are to detect/measure, prevent, or intervene in digital addiction. The trend shows that the detection theme is still the most researched topic in digital addiction research, while we found fewer studies in the prevention and intervention efforts. The IT used in selected studies can be categorized as applications, frameworks, AI methods, and biosignal recording systems. The trend also shows that the AI methods and biosignal recording systems are the two most used IT for digital addiction research, particularly in detection effort. The AI methods are used as a smart processing machine for various purposes including detecting, preventing, and intervening digital addiction. Whereas the biosignal processing systems are used to obtain human physiological data for further analysis. The applications found are mostly used to record user's usage behavior data for further analysis, except for One application that is developed to build user awareness of excessive smartphone use consequences. The proposed frameworks aim to guide the development of digital addiction intervention systems. The approach to the use of IT in detection, prevention, and intervention and the advantages and limitations of each approach are discussed.

Based on the trend found in this study, two main research directions are suggested as follows: (1) the utilization of IT for digital addiction prevention and intervention with various approaches may be further investigated in the future, and (2) the utilization of human physiological parameters and AI technology may still be further explored for developing an effective, reliable, and real-time system for combating digital addiction. Lastly, it should be noted that because of the researchers' access limitation, we only used the Scopus database to find the relevant literature. Therefore, some qualifying papers residing on other databases may have been missed.

Author Contributions: Conceptualization, F.S.R., L.E.N., R.F. and D.B.S.; methodology, F.S.R., L.E.N., R.F., and D.B.S.; validation, F.S.R., L.E.N., R.F. and D.B.S.; formal analysis, F.S.R.; investigation, F.S.R.; resources, F.S.R.; data curation, F.S.R.; writing-original draft preparation, F.S.R.; writing-review and editing, F.S.R., L.E.N., R.F. and D.B.S.; visualization, F.S.R.; supervision, L.E.N., R.F. and D.B.S. All authors have read and agreed to the published version of the manuscript.

Funding: This research received no external funding.

Conflicts of Interest: The authors declare no conflict of interest.

\section{References}

1. Griffiths, M.D. Technological addictions. Clin. Psychol. Forum 1995, 76, 14-19.

2. Griffiths, M. Does internet and computer "addiction" exist? Some case study evidence. CyberPsychol. Behav. 2000, 3, 211-218. [CrossRef] 
3. Alrobai, A.; McAlaney, J.; Phalp, K.; Ali, R. Online peer groups as a persuasive tool to combat digital addiction. In Proceedings of the 11th international conference on Persuasive Technologies, Salzburg, Austria, 5-7 April 2016; pp. 288-300.

4. Starcevic, V.; Aboujaoude, E. Internet addiction: Reappraisal of an increasingly inadequate concept. CNS Spectr. 2016, 22, 7-13. [CrossRef]

5. Young, K.S. Internet addiction: Evaluation and treatment. BMJ 1999, 319, 9910351. [CrossRef]

6. Andreassen, C.S. Online social network site addiction: A comprehensive review. Curr. Addict. Rep. 2015, 2, 175-184. [CrossRef]

7. Chóliz, M. Mobile phone addiction: A point of issue. Addiction 2010, 105, 373-374. [CrossRef] [PubMed]

8. Yen, J.-Y.; Ko, C.-H.; Yen, C.-F.; Chen, S.-H.; Chung, W.-L.; Chen, C.-C. Psychiatric symptoms in adolescents with Internet addiction: Comparison with substance use. Psychiatry Clin. Neurosci. 2008, 62, 9-16. [CrossRef] [PubMed]

9. Brand, M.; Young, K.S.; Elaier, C. Prefrontal control and internet addiction: A theoretical model and review of neuropsychological and neuroimaging findings. Front. Hum. Neurosci. 2014, 8, 375. [CrossRef]

10. Cham, S.; Algashami, A.; Aldhayan, M.; McAlaney, J.; Phalp, K.; Almourad, M.B.; Ali, R. Digital addiction: Negative life experiences and potential for technology-assisted solutions. Adv. Intell. Syst. Comput. 2019, 931, 921-931. [CrossRef]

11. Abbasi, I.S.; Alghamdi, N.G. When flirting turns into infidelity: The Facebook dilemma. Am. J. Fam. Ther. 2017, 45, 1-14. [CrossRef]

12. Abbasi, I.S. Social media addiction in romantic relationships: Does user's age influence vulnerability to social media infidelity? Pers. Individ. Differ. 2019, 139, 277-280. [CrossRef]

13. Moqbel, M.; Kock, N. Unveiling the dark side of social networking sites: Personal and work-related consequences of social networking site addiction. Inf. Manag. 2018, 55, 109-119. [CrossRef]

14. Jiang, Q. Internet addiction among young people in China: Internet connectedness, online gaming, and academic performance decrement. Internet Res. 2014, 24, 2-20. [CrossRef]

15. Chaudhury, P.; Tripathy, H.K. A study on impact of smartphone addiction on academic performance. Int. J. Eng. Technol. 2018, 7, 50-53. [CrossRef]

16. Lapointe, L.; Boudreau-Pinsonneault, C.; Vaghefi, I. Is smartphone usage truly smart? A qualitative investigation of it addictive behaviors. In Proceedings of the Annual Hawaii International Conference on System Sciences, Wailea, HI, USA, 7-10 January 2013; pp. 1063-1072.

17. Young, K.S. Internet addiction: The Emergence of a new clinical disorder. CyberPsychol. Behav. 1998, 1, 237-244. [CrossRef]

18. Altuwairiqi, M.; Kostoulas, T.; Powell, G.; Ali, R. Problematic attachment to social media: Lived experience and emotions. In Proceedings of the WorldCIST, Galicia, Spain, 16-19 April 2019; pp. 795-805.

19. Savci, M.; Aysan, F. Technological addictions and social connectedness: Predictor effect of internet addiction, social media addiction, digital game addiction and smartphone addiction on social connectedness. Dusunen Adam J. Psychiatry Neurol. Sci. 2017, 30, 202-216. [CrossRef]

20. Chung, S.; Lee, J.; Lee, H.K. Personal factors, internet characteristics, and environmental factors contributing to adolescent internet addiction: A public health perspective. Int. J. Environ. Res. Public Health 2019, 16, 4635. [CrossRef]

21. Cash, H.; Rae, C.D.; Steel, A.H.; Winkler, A. Internet addiction: A brief summary of research and practice. Curr. Psychiatry Rev. 2012, 8, 292-298. [CrossRef]

22. Doan, A.P.; Strickland, B. Hooked on Games: The Lure and Cost of Video Game and Internet Addiction; F.E.P. International, Inc.: Thornhill, ON, Canada, 2012; ISBN 193557602X.

23. Eyal, N. Hooked: How to Build Habit-Forming Products; Penguin Group (USA) LLC: New York, NY, USA, 2014; ISBN 9780698190665.

24. Alter, A. Irresistible: The Rise of Addictive Technology and the Business of Keeping Us Hooked; Penguin Group (USA) LLC: New York, NY, USA, 2017; ISBN 9781594206641.

25. Berthon, P.; Pitt, L.; Campbell, C. Addictive de-vices: A public policy analysis of sources and solutions to digital addiction. J. Public Policy Mark. 2019, 38, 451-468. [CrossRef]

26. Mihajlov, M.; Vejmelka, L. Internet addiction: A review of the first twenty years. Psychiatr. Danub. 2017, 29, 260-272. [CrossRef] 
27. Segawa, T.; Baudry, T.; Bourla, A.; Blanc, J.-V.; Peretti, C.-S.; Mouchabac, S.; Ferreri, F. Virtual Reality (VR) in assessment and treatment of addictive disorders: A systematic review. Front. Neurosci. 2020, 13, 1409. [CrossRef]

28. Park, S.Y.; Kim, S.M.; Roh, S.; A Soh, M.; Lee, S.H.; Kim, H.; Lee, Y.-S.; Han, D.H. The effects of a virtual reality treatment program for online gaming addiction. Comput. Methods Programs Biomed. 2016, 129, 99-108. [CrossRef] [PubMed]

29. Riva, G.; Wiederhold, B.K.; Di Lernia, D.; Chirico, A.; Riva, E.F.M.; Mantovani, F.; Cipresso, P.; Gaggioli, A. Virtual reality meets artificial intelligence: The emergence of advanced digital therapeutics and digital biomarkers. Annu. Rev. CyberTherapy Telemed. 2019, 17, 3-7.

30. Lam, L.T.; Lam, M.K. eHealth intervention for Problematic Internet Use (PIU). Curr. Psychiatry Rep. 2016, 18, 107. [CrossRef]

31. Ferreri, F.; Bourla, A.; Mouchabac, S.; Karila, L. e-Addictology: An overview of new technologies for assessing and intervening in addictive behaviors. Front. Psychiatry 2018, 9, 51. [CrossRef] [PubMed]

32. Piper, R.J. How to Write Systematic Review: A Guide for Medical Students. 2013. Available online: http: //sites.cardiff.ac.uk/curesmed/files/2014/10/NSAMR-Systematic-Review.pdf (accessed on 16 October 2020).

33. Armstrong, R.; Hall, B.J.; Doyle, J.; Waters, E. 'Scoping the scope' of a cochrane review. J. Public Health 2011, 33, 147-150. [CrossRef]

34. Briner, R.B.; Denyer, D. Systematic review and evidence synthesis as a practice and scholarship tool. In Systematic Review and Evidence Synthesis as a Practice and Scholarship Tool; Oxford University Press (OUP): Oxford, UK, 2012.

35. Kitchenham, B.; Ebse, C. Guidelines for Performing Systematic Literature Reviews in Software Engineering Executive Summary. 2007. Available online: https:/userpages.uni-koblenz.de/ \{\}laemmel/esecourse/slides/ slr.pdf (accessed on 16 October 2020).

36. Kitchenham, B.A.; Budgen, D.; Brereton, P. Evidence-Based Software Engineering and Systematic Reviews; CRC Press: Boca Raton, FL, USA, 2016; ISBN 9781482228663.

37. Uzun, B.; Tekinerdogan, B. Model-driven architecture based testing: A systematic literature review. Inf. Softw. Technol. 2018, 102, 30-48. [CrossRef]

38. Choi, J.; Rho, M.J.; Kim, Y.; Yook, I.H.; Yu, H.; Kim, D.-J.; Choi, I.Y. Smartphone dependence classification using tensor factorization. PLoS ONE 2017, 12, e0177629. [CrossRef] [PubMed]

39. Hafeez, M.; Idrees, M.D.; Kim, J.-Y. Development of a diagnostic algorithm to identify psycho-physiological game addiction attributes using statistical parameters. IEEE Access 2017, 5, 22443-22452. [CrossRef]

40. Wibirama, S.; Nugroho, H.A. Towards understanding addiction factors of mobile devices: An eye tracking study on effect of screen size. In Proceedings of the 2017 39th Annual International Conference of the IEEE Engineering in Medicine and Biology Society (EMBC), Jeju Island, Korea, 11-15 July 2017; pp. 2454-2457.

41. Kim, H.; Ha, J.; Chang, W.-D.; Park, W.; Kim, L.; Im, C.-H. Detection of craving for gaming in adolescents with internet gaming disorder using multimodal Biosignals. Sensors 2018, 18, 102. [CrossRef]

42. Yeo, M.; Lim, S.; Yoon, G. Analysis of biosignals during immersion in computer games. J. Med. Syst. 2017, 42, 3. [CrossRef]

43. Di, Z.; Gong, X.; Shi, J.; Ahmed, H.O.A.; Nandi, A.K. Internet addiction disorder detection of Chinese college students using several personality questionnaire data and support vector machine. Addict. Behav. Rep. 2019, 10, 100200. [CrossRef] [PubMed]

44. Hsieh, W.-H.; Shih, D.-H.; Shih, P.-Y.; Lin, S.-B. An ensemble classifier with case-based reasoning system for identifying internet addiction. Int. J. Environ. Res. Public Health 2019, 16, 1233. [CrossRef] [PubMed]

45. Ji, H.-M.; Chen, L.-Y.; Hsiao, T.-C. Real-time detection of internet addiction using reinforcement learning system. In Proceedings of the 2019 Genetic and Evolutionary Computation Conference Companion, Prague, Czech Republic, 13-17 July 2019; pp. 1280-1288.

46. Noë, B.; Turner, L.D.; Linden, D.E.; Allen, S.M.; Winkens, B.; Whitaker, R.M. Identifying indicators of smartphone addiction through user-app interaction. Comput. Hum. Behav. 2019, 99, 56-65. [CrossRef] [PubMed]

47. Chow, K.; Leong, B.D.; Lee, Y.H.B. Imagining consequences of excessive smartphone use via a character-based mobile application. Int. J. Ment. Health Addict. 2018, 16, 1420-1434. [CrossRef]

48. Alrobai, A.; Algashami, A.; Doğan, H.; Corner, T.; Phalp, K.; Ali, R. COPE.er method: Combating digital addiction via online peer support groups. Int. J. Environ. Res. Public Health 2019, 16, 1162. [CrossRef] 
49. Aggarwal, S.; Saluja, S.; Gambhir, V.; Gupta, S.; Satia, S.P.S.; Gupta, S. Predicting likelihood of psychological disorders in PlayerUnknown's Battlegrounds (PUBG) players from Asian countries using supervised machine learning. Addict. Behav. 2020, 101, 106132. [CrossRef]

50. Liu, W.; Mirza, F.; Narayanan, A.; Souligna, S. Is it possible to cure Internet addiction with the Internet? AI Soc. 2018, 35, 245-255. [CrossRef]

51. Probierz, E.; Gałuszka, A. Problematic use of the internet-Using machine learning in a prevention Programme. Commun. Comput. Inf. Sci. 2020, 231-238. [CrossRef]

52. Sama, H.R.; Kalvakolanu, S. Novel hybrid approaches to measure smartphone addiction-Application of statistical and triangular fuzzy techniques. J. Public Aff. 2020. [CrossRef]

53. Su, W.; Fang, X.; Miller, J.K.; Wang, Y. Internet-based intervention for the treatment of online addiction for college students in China: A pilot study of the healthy online self-helping center. Cyberpsychol. Behav. Soc. Netw. 2011, 14, 497-503. [CrossRef] [PubMed]

54. Lee, H.; Ahn, H.; Choi, S.; Choi, W. The SAMS: Smartphone addiction management system and verification. J. Med Syst. 2014, 38, 1-10. [CrossRef]

55. Jiang, F.; Jiang, Y.; Zhi, H.; Dong, Y.; Li, H.; Ma, S.; Wang, Y.; Dong, Q.; Shen, H.; Wang, Y. Artificial intelligence in healthcare: Past, present and future. Stroke Vasc. Neurol. 2017, 2, 230-243. [CrossRef] [PubMed]

56. Kuss, D.; Griffiths, M.D. Internet and gaming addiction: A systematic literature review of neuroimaging studies. Brain Sci. 2012, 2, 347-374. [CrossRef] [PubMed]

57. Kim, Y.-R.; Son, J.-W.; Lee, S.-I.; Shin, C.-J.; Kim, S.-K.; Ju, G.; Choi, W.-H.; Oh, J.-H.; Lee, S.; Jo, S.; et al. Abnormal brain activation of adolescent internet addict in a ball-throwing animation task: Possible neural correlates of disembodiment revealed by fMRI. Prog. Neuro-Psychopharmacol. Biol. Psychiatry 2012, 39, 88-95. [CrossRef]

58. Liu, J.; Li, W.; Zhou, S.; Zhang, L.; Wang, Z.; Zhang, Y.; Jiang, Y.; Li, L. Functional characteristics of the brain in college students with internet gaming disorder. Brain Imaging Behav. 2015, 10, 60-67. [CrossRef]

59. Kozliková, K.; Granja, C.; Leroy, C. Biological signals in medical diagnostics. In Proceedings of the AIP Conference Proceedings, Bratislava, Slovakia, 6-15 July 2009; Volume 1204, pp. 147-150.

60. Roberts, J.A.; Yaya, L.H.P.; Manolis, C. The invisible addiction: Cell-phone activities and addiction among male and female college students. J. Behav. Addict. 2014, 3, 254-265. [CrossRef]

61. Vondráčková, P.; Gabrhelík, R. Prevention of internet addiction: A systematic review. J. Behav. Addict. 2016, 5, 568-579. [CrossRef]

62. De Leeuw, R.R.J.; De Bruijn, M.; Oene, G.H.D.W.-V.; Schrijvers, G. Internet and game behaviour at a secondary school and a newly developed health promotion programme: A prospective study. BMC Public Health 2010, 10, 544. [CrossRef]

63. Shek, D.T.L.; Ma, H.K.; Sun, R.C.F. Development of a new curriculum in a positive youth development program: The project P.A.T.H.S. In Hong Kong. Sci. World J. 2011, 11, 2207-2218. [CrossRef]

64. Busch, V.; De Leeuw, R.J.; Schrijvers, A.J. Results of a Multibehavioral health-promoting school pilot intervention in a Dutch secondary school. J. Adolesc. Health 2013, 52, 400-406. [CrossRef]

65. Walther, B.; Hanewinkel, R.; Morgenstern, M. Effects of a brief school-based media literacy intervention on digital media use in adolescents: Cluster randomized controlled trial. Cyberpsychol. Behav. Soc. Netw. 2014, 17, 616-623. [CrossRef]

66. Byrnes, N. Treating Addiction with an App. Available online: https://www.technologyreview.com/s/604085/ treating-addiction-with-an-app/ (accessed on 16 October 2020).

67. Walravens, S. How This CEO Is Using Artificial Intelligence to Treat Addiction. Available online: https://www.forbes.com/sites/geekgirlrising/2017/11/02/from-addict-to-a-i-entrepreneur-how-this-ceo-isusing-technology-to-treat-addiction/\#5915f80d408e (accessed on 16 October 2020).

Publisher's Note: MDPI stays neutral with regard to jurisdictional claims in published maps and institutional affiliations. 